\title{
Taking stock of community-based flood risk management in Malawi: different stakeholders, different perspectives
}

\author{
Robert Šakić Trogrlić ${ }^{1}$, Grant B. Wright ${ }^{1}$, Adebayo J. Adeloye ${ }^{1}$, Melanie J. \\ Duncan $^{2}$, Faidess Mwale ${ }^{3}$ \\ ${ }^{1}$ School of Energy, Geoscience, Infrastructure and Environment, Institute for Infrastructure \\ and Environment, Heriot-Watt University, Edinburgh, United Kingdom
}

${ }^{2}$ Earth Hazards and Observatories, British Geological Survey (Natural Environment Research Council), Edinburgh, United Kingdom

${ }^{3}$ Polytechnic Blantyre, University of Malawi, Blantyre, Malawi

Corresponding author: Robert Šakić Trogrlić; e-mail: rs36@hw.ac.uk; Address: Institute for Infrastructure and Environment, School of Energy, Geoscience, Infrastructure and Society (EGIS), Heriot-Watt University, Edinburgh EH14 4AS, UK

Current flood risk strategies in Malawi are characterised by community-based flood risk management (CB-FRM), even though studies explicitly documenting evidence of successful CB-FRM remain limited. This paper investigates the realities and challenges of CB-FRM as seen through a lens of different stakeholder groups. In order to capture the experiences of CB-FRM in Malawi, a predominantly qualitative research framework was developed. In April 2016, eleven focus group discussions with stakeholder groups (local communities, local government and non-governmental organisations) were held. Additionally, informal discussions, field visits, a short survey and an extensive desk study were undertaken. The findings were analysed according to the major themes that emerged related to the realities and challenges of specific stakeholder groups. Although response and relief still remain prominent components of CB-FRM in Malawi, a number of mitigation and preparedness activities is observed. However, a lack of incountry resources, relief-oriented aid approaches and a 'aid dependency' syndrome represent obstacles. Different stakeholder groups share similar challenges, conditioned by their specific contexts, in terms of financing, participation, decentralised governance and project management. Lack of project sustainability and localised ownership also emerged as major challenges. The identified challenges have helped shed light on the 
frontiers and directions in which improvements are needed in Malawi, thus offering a valuable contribution to the existing knowledgebase.

Keywords: Malawi, floods, community-based flood risk management (CB-FRM), community-based disaster risk reduction (CB-DRR) 


\section{Introduction}

The frequency, intensity and extent of disasters continue to increase on a global scale, and exposure to natural hazards is growing at a faster rate than vulnerability is decreasing (UNISDR, 2015). Climate change, rapid population growth, environmental degradation and growing inequality are amongst the leading factors driving this increase in exposure, particularly in the context of the developing world (Habitat III Secretariat, 2015). Natural hazards pose a very real obstacle for development in Sub-Saharan Africa (SSA) (Chhibber \& Laajaj 2008), with floods and droughts alone accounting for $70 \%$ of disaster related economic losses (World Bank, 2010).

The SSA country of Malawi is particularly vulnerable to natural hazards (Nkomwa, Kalanda Joshua, Ngongondo, Monjerezi \& Chipungu, 2014), and it is estimated that the combined effect of floods and droughts reduces annual Gross Domestic Product by $1.7 \%$ (Pauw, Thurlow, Bachu \& van Seventer, 2011). Flooding is the most common disaster in Malawi, accounting for $\sim 40 \%$ of all recorded disasters (Nillson, Shela \& Chavula, 2010). Between 1967- 2013, 20 incidents of severe flooding have been reported (GoM, 2015a). Most recently, the floods of January/February 2015 affected some 1.1 million people, displacing 230,000 and leading to 170 fatalities and 172 reported missing (GoM 2015b; Rudari, Beckers, De Angeli, Rossi \& Trasforini, 2016).

In a country where $85 \%$ of the population is rural and the economy is overwhelmingly agro-based, the almost annual flooding occurrences significantly impact livelihoods as they directly affect income generated from agriculture (Shela, Thompson, Jere \& Annandale, 2008; Nillson, Shela \& Chavula 2010; Nkomwa et al. 2014). Recurrent floods also damage infrastructure, and impact local communities' social, economic, cultural and psychological values (Mijoni \& Izadkhah, 2009; Nillson et al., 2010). The projected future increase in the frequency and intensity of extreme weather events in the region (Chidanti-Malunga, 2011), 
coupled with a lack of coping capacity (Mijoni \& Izadkhah, 2009), mean that this situation will worsen unless more effective flood risk management strategies are devised.

Current flood risk management in Malawi relies on international funds from donors, which tend to facilitate community-based flood risk management (CB-FRM), implemented predominantly by non-governmental organisations (NGOs) (Nillson et al., 2010; Chiusiwa, 2015). CB-FRM belongs to the wider family of community-based disaster risk reduction (CBDRR) approaches, that have evolved over the past 30 years (Maskrey, 1989; Carby, 2015); such community-centred approaches incorporate local knowledge and perspectives into preparatory or anticipatory action to help create solutions that are cost-effective, sustainable, and generally more accepted by communities (Maskrey, 2011).

Although the improved resilience of communities exposed to hazards, including flooding, is seen as an imperative for future disaster risk reduction (DRR) in Malawi (Brown, 2011), research to date acknowledges the existence of CB-FRM rather than undertaking any detailed exploration of its setup, realities and challenges (Shela et al., 2008; Nillson et al., 2010; Mijoni \& Izadkhah, 2009; Mwale, Adeloye \& Beevers, 2015). The research presented herein addresses this current knowledge gap by focusing on CB-FRM in the most flood prone area of Malawi. It presents the findings of an extensive field study conducted in April 2016 to explore the realities and obstacles for community-based approaches for a range of different stakeholders in the region.

The remainder of the paper is organised as follows. Following a brief overview of the concept of CB-DRR (and by inference CB-FRM), the case study area and methodological approach are detailed. The results of the in-depth case study analysis are then presented, before the key conclusions are identified.

\section{The rise of community-based disaster risk reduction (CB-DRR)}


The idea that mere managing of disastrous events is not sufficient, and that there is a need to manage the risks shaping the disasters, gave rise to the term disaster risk reduction (DRR), which can be defined as "the concept and practice of reducing disaster risks through systematic efforts to analyse and manage the casual factors of disasters, including through reduced exposure to hazards, lessened vulnerability of people and property, wise management of land and the environment, and improved preparedness for adverse events" (UNISDR, 2009, p. 10). In addition to DRR, the literature on disasters and community-based approaches often refers to community-based disaster risk management (CB-DRM). As explained by Shaw (2012, p. 5): “CB-DRM and CB-DRR are often used with similar meaning, with enhanced focus on 'risk'; however, there still exists a thin line of distinction. While CB-DRR focuses more on pre-disaster activities for risk reduction by the communities, CB-DRM focuses a broader perspective of risk-reduction-related activities by communities, both during, before, and after the disaster." This paper draws its theoretical foundation and research design both from DRR and DRM literature, but uses the term DRR, in accordance with the recently adopted Sendai Framework for Disaster Risk Reduction 2015-2030 (UNISDR, 2015).

Traditionally, disaster research was characterized by a hazard paradigm (Hewitt, 1983), focusing on the physical and natural science components of disaster risk and explaining disasters as events shaped by natural hazards (Mercer, Kelman, Llyod \& SuchetPearson, 2008; Gaillard \& Mercer, 2013). In the 1970s, there was greater recognition that disasters are more a consequence of socio-economic rather than natural factors (O'Keefe, Westgate \& Wisner, 1976), which opened a new era of vulnerability paradigm, understanding that peoples' vulnerability to disasters is shaped by interconnected underlying social, economic, political and cultural processes (Blaikie, Cannon, Davis \& Wisner, 1994; Wisner, Blaikie, Cannon \& Davis, 2004). Local communities at risk have the greatest deal to lose when disaster strikes, but also the most to benefit from risk reduction activities (Shaw, 2006; 
Jahangiri, Izadkhah \& Tabibi, 2011); hence, DRR is fundamentally a local affair (Maskrey, 2011).

During the paradigm shift, there was also a move from top-down approaches (i.e. command and control) which focused on response and relief, to an emphasis on more proactive, community-based and bottom-up approaches focusing more on risk mitigation, preparedness and the role of individuals and communities (Scolobig, Priot, Schoter, Jorin \& Patt, 2015). Top-down approaches often do not adequately address the vulnerabilities of those at risk (Bollin \& Hidajat, 2013) or harness participation of the vulnerable, and consequently they often fail (Mercer, Kelman \& Dekens, 2009). On the other hand, bottomup approaches normally involve vulnerable local communities at all stages, recognising them as a resource, with abundant local knowledge, skills, and capacities that can be used to effectively mitigate the risks and impacts of hazardous events (Dekens, 2007; Dumaru, 2010; Gaillard \& Mercer, 2013). However, no model is appropriate for all local contexts and hazard circumstances (Scolobig et al., 2015), and bottom-up approaches can stay mere narrative on the national and local levels, whilst top-down approaches still dominate (Gaillard \& Mercer, 2013).

Community-based approaches, such as CB-FRM, are based on participatory approaches, seen as a cornerstone of successful DRR at the local level (Twigg, 2009; Kienberger, 2013). In CB-DRR, communities are supported in identifying risks, selecting and prioritizing solutions, implementing solutions and monitoring their operation. This has the potential to lead to more sustainable solutions and increased local resilience through: empowerment of communities, vulnerability reduction, strengthening of local capacities, local ownership and increased local cohesion (Maskrey, 1989; Shaw, 2006; Gero, Méheux \& Dominey-Howes, 2011; Maskrey, 2011). The CB-DRR literature sees communities as the primary actors with the efforts generally led by NGOs, however stakeholders also include 
local governments, national government, civil society actors (i.e. other than NGOs) and local business sectors (Shaw, 2006; Maskrey, 2011).

Although the application of CB-DRR is increasing, especially in the developing world, such approaches are not without challenges. As stated by Maskrey (2011), communityapproaches are very often done 'at' community levels rather than 'with' community or local ownership. Whilst discussing African experiences in CB-DRR, van Niekerk \& Coetzee (2012) identified a range of emerging issues, namely: lack of governance structures and institutional frameworks for implementation; the largely top-down approach followed by many governments; lack of political will for DRR activity; lack of financial and human resources to carry out CB-DRR; training and skills deficiencies of DRR officials; and, lack of multiple stakeholder involvement in some regions/countries. The situations in Asia and South America are not dissimilar to that of Africa, and the literature identifies further challenges in these regions including: lack of project sustainability; inadequate participation and ownership by communities; and, lack of best practices up-scaling (Shaw, 2006; Maskrey, 2011). Experiences from these regions also indicate that CB-DRR is rarely incorporated into policy and often does not tackle the underlying causes of vulnerability, such as the lack of access to land and social inequality (Shaw, 2006; Maskrey, 2011).

Despite the presence of CB-DRR for several decades, the outlined challenges reveal the need for new approaches based on a detailed understanding of the current setup and its shortfalls. As argued by Shaw (2012), sharing and up-scaling of 'champion' practices exercised at local levels remains a major challenge, despite its significant potential for disaster vulnerability reduction in different geographical settings. And whilst CB-DRR is aimed at resilience building of communities at local levels, its sustainability, effectiveness and replicability directly depend on broader local and national policy and strategies (Shaw, 2012). Current policies and ideologies, responsible for vulnerability creation at local levels across the 
world, can be challenged if CB-DRR is mainstreamed into the wider development adequately (Heijmans, 2009).

The review presented above demonstrates that, despite its increased application, CBDRR in general continues to experience challenges that undermine its effectiveness. The present research, with its focus on the local level in rural Malawi, will contribute to the evidence base around the realities of one particular form of CD-DRR (i.e. CB-FRM) in the developing world, with a special application for Sub-Saharan Africa context.

\section{Methods}

Guided by questions on the status and challenges for CB-FRM in Malawi, as viewed through the lens of different stakeholders, the research adopted a predominantly qualitative, in-depth research framework. It employed case-study research design (Bryman, 2012), which is considered effective for a detailed examination of factors at the local level (Pardoe, Kloos \& Assogba, 2016) and has been successfully used for in-depth analysis of DRR at local level in many diverse situations (e.g. Mercer, 2010; Mercer, Kelman, Taranis \& Suchet-Pearson, 2010; Hiwasaki, Luna, Sysamsidik \& Shaw, 2014; Nkomwa et al., 2014).

\section{Case study area}

The fieldwork was conducted in the Nsanje and Chikwawa Districts of the Lower Shire Valley in the southern part of Malawi (Figure 1). Together, these districts form an area of approximately $6700 \mathrm{~km}^{2}$ (Chidanti-Malunga, 2011). According to the census data from 2008, Chikwawa has a population of approximately 436.000 and Nsanje of 240.000 (National Statistical Office, 2009). Approximately $80 \%$ of the population lives below the poverty line, exceeding the national average of 50.7\% (National Statistical Office, 2012). These districts were chosen for two main reasons: they are the most flood prone areas of Malawi, 
experiencing significant flooding on an almost annual basis, and the project team had good existing contacts in the two districts.

The hydrology of the Lower Shire Valley is dominated by the Shire River, the only outlet of Lake Malawi. Flooding in the region tends to be caused by flooding of the Shire River itself, flash flooding of the Ruo River and backwater effects from the Ruo River joining the Shire River (Nillson et al., 2010; Atkins, 2011).The average annual flow of the Shire is $450 \mathrm{~m}^{3} / \mathrm{s}$ and of the Ruo is $54 \mathrm{~m}^{3} / \mathrm{s}$, with recorded flows as high as $1430 \mathrm{~m}^{3} / \mathrm{s}$ and $5400 \mathrm{~m}^{3} / \mathrm{s}$ respectively (Shela et al., 2008; Mwale et al., 2015). Severe flooding occurred in 1956, 1997, 2001, 2002, 2003, 2005, 2006, 2012 and 2015 (Mijoni \& Izadkhah, 2009; Chikwawa District Council, 2014; Rudari et al., 2016). In addition to major events, annual flooding episodes are estimated to affect up to 100 and 500 households in Chikwawa and Nsanje respectively (Chikwawa District Council, 2014; Nsanje District Council, 2015); coupled with the highest poverty levels in the country, this perpetuates the disaster-poverty cycle (Chidanti-Malunga, 2011). Overall, it has been demonstrated that flood hazardousness in the valley falls into medium to high categories (Adeloye, Mwale \& Dulanya, 2015).

Whilst quantifying vulnerability of rural communities to flooding in the Lower Shire Valley, Mwale et al. (2015) suggested that vulnerability is shaped predominantly by socioeconomic and environmental susceptibility. In other words, communities in the Lower Shire Valley lack economic resources and employment opportunities, as well as demonstrating low levels of literacy alongside high levels of poverty and environmental fragility.

\section{Data collection and analysis}

Fieldwork was undertaken in April 2016, a year after the extreme 2015 floods, and whilst the country was still experiencing the El-Nino induced drought. Both of these events had the effect of raising the general profile of DRR in the country among all stakeholders. 
The primary data was gathered through focus group discussions (FGDs), which have the potential to generate additional information in the community setting (Bazeley, 2013) and are suited to general project logistics (e.g. duration of fieldwork, ease of access to stakeholders, collecting diversity of views). In total, 11 FGDs were held with different stakeholder groups (Table 1), namely: local communities (Village Civil Protection Committees, VCPC); NGOs; and, local government (District Civil Protection Committee, DCPC). Initial identification of communities was undertaken through a DoDMA district level staff contact, and researchers were accompanied at all times by a member of the DCPC who acted as a facilitator. The communities visited were selected on the basis of the severity and frequency of flooding, as well as being beneficiaries of CB-FRM related projects. FGDs participants were primarily selected using purposive sampling (i.e. selection of participants directly relevant to research aims), except for one FGD with NGOs in Nsanje, where opportunistic sampling (i.e. capitalising on opportunities to collect data) was employed (Mason, 2010, Bryman, 2012). Questions covered five main themes, namely: flood experiences; on-going, community-level related activities and projects; the roles of different stakeholders; the main CB-FRM challenges; and, recommendations for improving current procedures. Following the FGDs, participants from DCPCs and NGOs (30 respondents) were asked to a complete a short written survey, consisting of closed and open-ended questions regarding the community-level activities they are involved with.

Translation from Chichewa to English and additional facilitation was provided by a Malawian member of the research team. All FGDs were audio recorded, transcribed, coded and analysed using thematic analysis (Bryman, 2012). Following the main research aim, the major themes were created according to the realities and challenges of specific stakeholder groups, with further thematic grouping within specific stakeholder groups. 
Whilst FGDs were the primary data source, additional data were also collected through informal discussions with local facilitators and through field visits, both to FRM related projects (e.g. community-built dikes, reafforestation plots, rainfall gauges) or to see the impacts of the 2015 floods. These additional data-gathering activities, led by local actors, proved invaluable in building an accurate picture of the reality of CB-FRM in Nsanje and Chikwawa. The field visits and informal discussions were registered in a form of comprehensive note taking and photographic evidence.

A case study approach asks for data collected from multiple sources and triangulation (e.g. Smucker \& Wisner, 2008). Hence, in addition to the data collection methods described above, an extensive desk study was conducted to review policy documents and consultancy reports related to DRR in Malawi.

\section{Results}

This section first introduces the legal and policy context for DRR in Malawi, in order to understand the extent to which DRR is integrated at national level, before focussing on the views of different CB-FRM stakeholders.

\section{Legal and policy context for DRR}

A review of legal and policy context in Malawi indicates that DRR is mainstreamed into policy levels (Chiusiwa, 2015) and acknowledged as key for resilience building at the community level. Currently the main legal document for DRR is the Disaster Preparedness and Relief Act of 1991, which is considered to focus more on relief (Atkins, 2011) than the recent shift towards more proactive risk management. In 2015, the National Disaster Risk Management Policy (NDRMP) was adopted as the main framework guiding implementation and coordination of DRR in the country (GoM, 2015c), and DoDMA is currently in the process of creating a Disaster Management Bill, as a more long-term replacement for the Disaster Preparedness and Relief Act. 
The NDRMP aims to "sustainably reduce disaster losses in lives and in the social, economic and environmental assets of individuals, communities and the nation" (GoM, 2015c, p. 4). It has six priority areas, namely:

1) mainstreaming DRR into sustainable development;

2) establishment of a comprehensive system for disaster risk identification, assessment and monitoring;

3) development and strengthening of a people-centred early warning system;

4) promotion of a culture of safety, and adoption of resilience-enhancing interventions;

5) reduction of underlying risks; and,

6) strengthening preparedness capacity for effective response and recovery.

The associated implementation of policy goals, outcomes and priorities will require multi-sectoral commitment, political will, institutional and legal frameworks and the availability of resources (GoM, 2015c). Besides the NDRMP, other policies acknowledge the importance of DRR to sustainable development; for example, Malawi's most recent national development blueprint (Malawi Growth and Development Strategy II, 2011- 2016) acknowledges the need for DRR under the Social Support and Disaster Risk Management theme (GoM, 2010), and the policy guiding implementation of climate change adaptation activities (National Adaptation Programmes of Action) identifies activities related to increasing the capacity of rural communities to extreme weather events as one of the priority areas (GoM, 2006).

In line with the Local Government Act and Decentralisation Policy (1998), Malawi has a decentralised governance setup (Figure 2), providing local governments with administrative and political power, and empowering communities to participate in governance and development initiatives (Waylen \& Martin-Ortega, 2013). Local government structures are at the District level, Area level and Group Village level, with the District Level being the 
basic planning and implementation unit (Chiusiwa, 2015). Decentralised institutional system envisions that at all levels prepare and update Contingency Plans and Disaster Risk Management Plans; the plans created at Group Village Head (GVH) level feed into plans created at the Area level, that in turn feed into District level plans. Civil Protection Committees (CPCs) at all levels coordinate and implement DRR activities and policies, and advise the District Executive Committee on disaster issues (GoM, 2015c). The Agency coordinating DRR at the national level is the Department of Disaster Management Affairs (DoDMA), and its mandates at the local (i.e. district) levels are coordinated by Assistant Desk Officers for DRR; with a primary responsibility of coordinating the DRR activities and implementation of the NDRPM at the district level; making sure that localised activities are in line with the guidelines from the national level. The DCPC, among other responsibilities, is in charge of coordinating and overseeing the work of decentralised governance structures at lower administrative levels (i.e. Area and GVH levels) and liaise with the national agency (i.e. DoDMA).

However, despite clear institutional structures and the existence of planning documents, there are no readily available funds for the operation of DoDMA (Chiusiwa, 2015), and institutions rely on NGOs and donors to fund implementation of plans (Waylen \& Martin-Ortega, 2013). Indeed, NGOs play a key role in DRR in the Lower Shire Valley (Mijoni \& Izadkhah, 2009), and are effectively the main actors addressing the underlying causes of vulnerability with a view to building long-term resilience (Chiusiwa, 2015). Besides institutional stakeholders, GoM (2015c) lists a number of other stakeholders actively involved in DRR activities in the country, including: civil society, the private sector, development partners, media, academia, research institutions and communities.

\section{Challenges for different stakeholders}


Analysis of the collected data highlighted that although individual stakeholder groups identified a range of different challenges, they all identified both internal (endogenous) challenges connected to their own group, and external (exogenous) challenges through interaction with other stakeholder groups. This insight highlights an interesting theoretical distinction between the internal and external factors that influence stakeholder behaviour, and by extension policy change and practice. In general terms, Howlett and Cashore (2009) argue that, contrary to current thinking that policy change occurs primarily through homeostatic processes, significant change can also occur through a number of different mechanisms, each of which attributes varying degrees of significance to endogenous and exogenous factors. More pertinently, in the context of vulnerability and adaptation to climate change, Brooks (2003) cautions against viewing systems (e.g. households, communities, nations) as closed, and highlights the need to account for exogenous as well endogenous factors when considering how to facilitate the adaptation process.

Within this context, the identified challenges detailed below are classified either as internal or external.

\section{Local communities}

Community representatives from Village Civil Protection Committees (VCPCs) emphasised the creation of the Village Contingency Plans and Village Action Plans as one of their primary roles, where they identify and analyse hazards and risks, before selecting and ranking various risk reduction options. In addition, communities highlighted their involvement in a wide range of practical activities, such as: installing river training works, planting trees and grass, capacity building training, disseminating warning messages (official and indigenous), search and rescue, distribution of relief items and coordination of recovery activities. Even though the literature emphasises the focus on response and recovery phases in Malawi (e.g. Shela et al., 2008; Mijoni \& Izadkah, 2009; Nillson et al., 2010), these findings indicate a 
number of proactive, risk mitigation and preparedness activities; for example, the installation of water level and rainfall gauges as a part of community-based early warning systems, extensive reafforestation programmes and training to operate equipment and communicate warning messages, was noted across a number of different communities.

Internal challenges for local communities relate to characteristics and situation of the community, whist external challenges relate to their interaction with NGOs and government. Despite participants' willingness to be involved in the long-term, they lack resources, which was often referred to as an internal challenge:

'We have human capital, but need support with other resources' (Female villager, Bitrinyu, Nsanje)

For instance, even though communities are aware of a need to build a dike and can provide labour, there is a need for external inputs (e.g. materials and capacity building for long-term maintenance).

Capacity building was identified as another internal challenge, with participants emphasising a lack of capacity in elements of DRR and climate change adaptation. Existing programmes (e.g. capacity building programmes, such as early warning message dissemination or search and rescue training) are considered to be tailored towards individuals, rather than a whole VCPC as a formal institutional structure, which in tandem with the 3 year tenure of VCPC members can effectively mean that the very body tasked with DRR coordination at the local level does not actually have adequately trained and/or equipped personnel to deal with a flood event; this was highlighted as a contributing factor to the impacts of the 2015 floods.

Finally, the identification of project beneficiaries was repeatedly raised as an internal challenge. FGD participants felt that even though the selection of beneficiaries (e.g. households receiving relief items or individuals working on dike construction) is their 
responsibility, their role is often overlooked, due either to power relations within communities or a need to validate their selection in front of the whole community, with one male villager from Nyan'ga, Nsanje stating that 'the process undermines their integrity'. Moreover, being a member of the VCPC often excludes them from being a project beneficiary, since the common perception by other community members is that they already benefited from having a role in $\mathrm{VCPC}$.

With respect to external challenges, participants were concerned that, what they perceive to be their rich local knowledge, is often disregarded by project implementers in favour of professional and scientific knowledge:

'Lack of our involvement means lack of our indigenous knowledge. So, there will be many deficiencies as far as the project life is concerned'. (Male villager, Mbenje, Nsanje)

Participants felt that they (as communities) are involved in the project inception phase, but are often side-lined and 'not be able to have a say' (male villager, Nyan'ga, Nsanje) in later phases. In some cases, participants felt that if a project deviated from its original remit, they would have no power to influence the process. However, in other discussions, a differing perspective was offered through an example of communities having a mandate to temporarily halt a project

'There was a contractor coming here. But [...] he was stealing some cement. So we stopped him from coming again'. (Male villager, Nyathando, Nsanje)

Further concern was raised about the appointment of external, as opposed to internal, personnel to implement project plans. This includes project "task forces" who are often employed to monitor and evaluate projects without any local insight, and government appointed contractors whose lack of adequate expertise and local knowledge often resulted in sub-standard work. 
'Normally, they will be people from other areas, so they do not care much for quality [...]. They [contractors] have a very limited capacity, so completion of the work is a challenge'. (Female villager, Nyathando, Nsanje)

In some cases the quality of work was thought to be undermined by the illegal loss (i.e. selling) of purchased materials during project implementation, whilst in other cases projects were simply not completed due to insufficient funds.

Communities identified further external challenges related to NGOs, including a lack of budget transparency:

'NGOs say they will spend a certain amount, but the work they do is different from the budget. There is no transparency on the budgeting' (Male villager, Birtinyu, Nsanje), and duplication of effort due to poor communication at the district level:

'... some organisation may bring food, and then some other organisations as well bring food, when what we need is, for example, blankets. That is quite common'. (Male villager, Medram, Chikwawa)

In one community it was noted that flood risk reduction projects are largely implemented in downstream, low-lying areas, with no or potentially detrimental actions undertaken further upstream; an example was given of an upstream area where environmental deforestation occurs, consequently increasing overall surface runoff, and undermining the effectiveness of downstream practices.

\section{Non-governmental organisations}

During the fieldwork, many NGOs were seen to be operating in the Lower Shire Valley, predominantly using participatory methodologies to support communities in developing local level DRR plans. Examples include: community-based early-warning systems, communityled dike construction and capacity-building activities (e.g. resilient building training, first aid, village savings and loans). NGOs highlighted the close cooperation with the DCPC in DRR 
issues, with the selection of project areas being based on guidance from district level government. Furthermore, NGO participants elaborated that the approach they take in their work with the local government is multi-sectoral, with technical expertise from relevant local government departments being brought in to contribute to specific projects (e.g. forestry officers advise on reafforestation programmes). This multi-sectoral approach further manifests itself in the co-production of seasonal scenarios as an input for the update of district-wide contingency plans, a collaborative exercise involving different government departments and NGOs.

Internal challenges for NGOs relate to how individual NGOs operate and coordinate with development partners and other NGOs, whilst external challenges relate to their interaction with communities and local government. Several internal challenges were associated with the working relationship between NGOs and their donors. For instance, even though a shift towards a more proactive approach to risk reduction is appearing, NGOs are currently still more focused on the response phase. A possible explanation for this is that contingency plans at district levels do not have designated funding, and donor financial assistance only tends to be available when disaster strikes. Additionally, NGO participants also felt that their organisations 'act and dance to the tunes of donors' (NGO member, Nsanje), since donor funded projects often arrive as 'pre-designed' packages, reflecting donors agendas rather than matching the actual needs of communities at risk. These findings have been noted elsewhere (e.g. Stephenson \& Penn, 2005).

NGO participants also highlighted the impact of unconventional behaviour of some NGOs, who often start activities within a village without using the established system for selecting areas for project implementation: 
'Most of the NGOs work with the government and that is very right. [...] But there are some challenges. There are NGOs that just come without passing the offices. [...] That is why most of the projects are sometimes abandoned.' (NGO member, Nsanje) It was noted that this often leads to duplication of efforts in certain areas, a paucity of activity in others and a general decrease in community confidence in NGO-related activities.

Data and information sharing between different NGOs and international development partners was also identified as a significant internal challenge, with most project reports submitted to respective headquarter offices without sharing with other development partners or local government, even though it is 'legally binding' (NGO member, Nsanje). This situation can again lead to duplication of efforts, a prime example being the commonplace duplication of Participatory Rural Appraisals (PARs) by different NGOs. Data protocols were also mentioned in relation to rainfall data from community-based gauging stations, with NGO members indicating that rainfall data collected by communities in the rainy season are not being stored by the Malawi Department of Climate Change and Meteorological Services. In a country that lacks the data required to calibrate the type of flood risk models needed to develop risk-informed localised strategies, this would appear to be a significant oversight.

In their work with communities, one of the major external challenges identified by NGO participants was the aid 'dependency' syndrome, whereby communities become so used to receiving assistance that they cease to develop their own long term resilience. The aid 'dependency' syndrome is seen as an anti-developmental process (Ali, Malwanda \& Suliman, 1999; Andrews, 2009). For example, NGOs report that cooperation with communities is in some cases negatively influenced by expectation of inputs (e.g. financial, food, materials) for work done for a communal cause. In a similar vein, NGOs also noted that communal projects tended to experience more significant challenges related to a lack of ownership, than individually focussed projects. An example of community-led planting alongside river banks 
was given, which NGOs often perceive to struggle because 'nobody owns the river' (NGO member, Nsanje) and it is hence difficult for villagers to understand how such measures benefit them individually. NGOs emphasised the importance of power relations within communities, which were often seen to bias the selection of project beneficiaries (e.g. family members selected to committees such as VCPC) and, by definition, the success of the project at a community level. NGO staff also noted that community members still perceive DRR as a matter of relief item distribution, whilst actual risk reduction remains ' $a$ word of mouth' (NGO member, Nsanje) in the absence of action and leadership instilled in existing community structures. Finally, NGO members pointed out that district government should revisit allocation of the project areas in the district, since there are areas which are not covered by the work of NGOs, thus creating unequal spatial coverage of CB-FRM activities.

Some challenges manifest as both internal and external. One of the most significant overall challenges identified by NGO participants was the general lack of sustainability and community ownership of the projects, and local government was identified as a key actor in this respect:

'As NGOs we are time specific. Projects have specific duration and then we are out. So, to make sure that activities or interventions [...] are sustainable, we need government personnel because they are there forever [...] Go there (to project sites) three, four years later and you will find that whatever was there is gone.' (NGO member, Nsanje).

The absence of adequate exit strategies, was also identified as a contributing factor to the lack of sustainability and community ownership of projects:

'... NGOs come in with exit strategies too late [...] We need to put in measures so that the actions we have been doing continue [...] Exit strategy should be there when you are starting the project. [...] Normally, I think that even communities themselves do not see it as a product. Unless, the facilitation is like that people realise: ok, this is our own. To put in these 
exit strategies, and that we have sustainable activities going on, and this owned by

communities themselves, it is coming too late'. (NGO member, Nsanje)

\section{Local government}

Local government participants (i.e. DCPC) identified a wide range of DRR-related activities undertaken by District Civil Protection Committees (DCPCs), including: the mobilisation of resources; information sharing through decentralised structures; training of Civil Protection Committees (CPCs) at different levels; identification of potential disaster prone areas; development of Contingency Plans and Disaster Risk Management Plans at district level; directing NGOs to projects sites; and, impacts and needs assessments.

Internal challenges for local government stakeholders relate to governmental work, whilst external challenges relate to their interaction with communities and NGOs. On a pathway of delivering DRR benefits, local government participants highlighted a lack of internal funding as the main challenge. As reported by Chiusiwa (2015) in the national progress report on the implementation of the Hyogo Framework for Action in Malawi, there are no budget lines for DRR at any level, with scarce Government resources tailored towards response and recovery, leaving mitigation and preparedness underfunded. In addition, some members of the DCPC highlighted that the lack of a dedicated budget line for DRR is one of the reasons that some areas in the districts are not beneficiaries of the projects, as local government has no financial capacity to support risk reduction projects implementation in areas where NGOs are not operating. The lack of funding resources also directly influences the capacity of the CPCs at all levels to annually update Contingency Plans; as an example, the latest version of the Contingency Plan for Chikwawa District was created for the 2014/2015 season. The Disaster Risk Management Plans at all levels were not available during the time of data collection for this study. Another internal challenge to delivering 
sustainable CB-FRM was that not all ministries are involved in the planning process. For example, representatives from the Ministry of Health and the Ministry of Gender, Children, Disability and Social Welfare felt that their role is often overseen in mitigation and preparedness planning, and it is not until after flooding has occurred that the need for their involvement becomes clear.

In terms of external challenges, funding often remains a challenge when projects are externally funded. DCPC members indicated that funding is often not available for DCPC to independently monitor projects, which in turn can influence the quality of delivered projects:

'The issue is money, we do not have it. We depend on the same donors, same NGOs to spare some money for us, so we can do the monitoring'. (DCPC member, Nsanje)

Another external challenge identified was the lack of participation and long-term commitment of community members to CB-FRM projects, with one DCPC member (Chikwawa) stating that 'When the project is phased out, that is when participation ends'. Participants felt that a more bottom-up approach, where communities submitted their own requests and ideas for risk reduction projects, would increase the sense of ownership of projects, which would in turn enhance the sustainability of projects. However, some participants emphasized that there is often no or very little capacity within communities to undertake long-term maintenance, since they do not normally receive any training:

'Most constructors, they do not train the communities so they are able to monitor the projects [...] The training would enhance participation' (DCPC member, Nsanje).

Building on the perceived participation gap and connecting with the 'dependency' syndrome, participants indicated that participation-resistance from communities is often experienced. It was suggested that communities' expectation of inputs (e.g. monetary, material, livestock) was the 'root cause of the problem' (DCPC member, Chikwawa). 
Participants also raised the issue of the dominance of people with power, with some individuals sitting on several committees in the communities (e.g. VCPC, Village Natural Resources Management Committees), with a DCPC member in Chikwawa noting that 'the participation is not equal and fairly spread within the community'. In addition to the questionable merit in investing power with a small group of individuals, an indirect implication of this situation is that institutional structures may not always operate as designed, e.g. the few individuals who received capacity building training will not be always available.

Whilst acknowledging the important role that NGOs play in the CB-FRM, participants highlighted several challenges related to their involvement. This included unconventional project selection processes that often lead to duplication of efforts in some areas and paucity of activities in others. According to participants, it is essential to follow the conventional system, particularly during the response phase, and failure to do so often creates chaos in the field. Furthermore, participants felt that there is a need for increased accountability of NGOs towards the local government, including budget transparency. Finally, there was an overall agreement that there is a necessity to improve the effectiveness of existing systems through better cooperation, coordination and communication between core actors (i.e. local government and NGOs).

\section{Discussion and conclusions}

The aim of the research presented herein was to explore the realities and challenges of CBFRM in in Malawi by engaging with different stakeholders groups in the most flood prone area: the Lower Shire Valley. The general findings are summarised in Table 2 and indicate that an enabling institutional, policy and legislative environment currently exists for DRR in Malawi. However, as stated by Mijoni and Izakhari (2009), even though Malawi has a holistic policy for flood hazard, its implementation is oriented toward relief assistance. The findings herein indicate that, although response and relief still remain prominent components, various 
activities on mitigation and preparedness can be observed, and such activities are strongly advocated by the local government and NGOs. However, the widespread lack of governmental resources for mitigation activities, allied to relief oriented donor interventions and aid dependency by communities pose difficulties in mainstreaming this shift to a 'business as usual' case. In line with previous research (e.g. Mijoni \& Izadkhah 2009), the results also show that the implementation of localised practices is led by NGOs, with international NGOs in particular playing a crucial role in funding community-based projects.

Results revealed a wide range of challenges experienced in the process of CB-FRM in Malawi, with each stakeholder group providing unique perspectives, based on local contexts and experiences. Notwithstanding some clearly identified differences, such as the project sustainability issues identified as a key challenge by NGOs and local government but not by local communities, the findings indicate that each of the stakeholder groups face similar challenges. Most notably, these challenges are experienced in terms of financing, participation, governance and community-based project management (from onset to operation and maintenance). Furthermore, all groups experience challenges in terms of coordination, both within their stakeholder group or through interaction with others.

Analysis of the data related to CB-FRM challenges highlighted the homogeneity in answers, as evidenced by similar experienced challenges, particularly in the FGDs conducted with NGOs and institutional stakeholders. Conversely, some heterogeneity and a lack of consensus between different local communities were observed, as evidenced by differences in the role of individual communities in influencing project implementation ). Furthermore, it was noted that challenges between two different districts (i.e. Nsanje and Chikwawa) analysed in this study are not distinct, which can be explained by similar flooding experiences and system in place in the districts (i.e. presence of NGOs, institutional setup). 
In terms of the different stakeholder roles, the findings show that CB-FRM in Malawi is often a truly multi-stakeholder effort. The decentralised institutional system for DRR in Malawi provides a platform for cooperation between government, civil society, local communities and other stakeholders. This was also found in a review of African experiences in CB-DRR, where van Niekerk \& Coetzee (2012) discuss flood mitigation construction in Chikwawa as a successful example of CB-FRM project. However, as findings in this paper indicate, this would appear to be an exception, as continued involvement and ownership presents one of the key obstacles for sustainable CB-FRM in Malawi. Shaw (2012) explains a lack of sustainability in CB-DRR by the lack of partnerships, participation, empowerment and ownership of local communities. Furthermore, the results revealed that the existing decentralised system in Malawi is in need of improvement, especially in terms of participation, transparency, accountability and collaboration; all universally seen as 'ingredients' of good governance (UNESCAP, 2009). The challenges of decentralisation that emerged as a result of this research are not unique for Malawi, and have been observed across the developing world (e.g. Grindle, 2004; Grady, Gersonious \& Makarigakis, 2016). The findings of this research clearly indicate that if CB-FRM, and more generally CB-DRR, is to progress from short-term and short-lived interventions towards more long lasting activities, collaborative efforts need to be taken by all stakeholder groups. Taking into account that efficient DRR requires a multi-sectoral approach and commitment from all parties (e.g. UNSIDR, 2015), it is evident that inadequate inclusion of all governmental sectors (e.g. health, gender) can present an obstacle for sustainable CB-FRM.

The limitations of this research were primarily concerned with data collection and, whilst the realities of qualitative social research mean that they could not be fully avoided, they were minimised whenever possible, particularly by having a local facilitator to act as a person of trust for communities and data triangulation. Significant efforts were made to 
ensure accurate transcribing and translating of FGDs, however real-time translation was problematic and may have resulted in the loss of some information or nuance. The quality and amount of data were in some cases influenced by the experience of local FGD facilitators and their rapport with communities. Cultural factors, such as the presence of community outsiders (researchers) or village chiefs, may also have had an impact on the information shared in the discussions. More specifically, the cancellation of an NGO meeting in Chikwawa meant that some NGO data was not gathered, although this was partially offset by the presence of NGO staff members on the DCPC in Chikwawa. Finally, logistical constraints meant that the research focused on three key stakeholder groups (local communities, NGOs and local government) and did not include representatives from either academia or the private sector who can be important stakeholders in CB-DRR (Shaw, 2012 ).

The research reported herein has revealed the challenges experienced by a range of different stakeholders involved in CB-FRM, and has hence helped identify areas for improvement in Malawi, particularly with respect to the development of the type of localised DRR strategies that are required to ensure the long-term sustainability of FRM measures. This is especially relevant for NGOs and local government, who continue to be the main coordinators and implementers of CB-FRM within Malawi. The study contributes to the literature on CB-FRM, and CB-DRR more widely, by adding a systematic overview and an in-depth analysis of a case study from Sub-Saharan Africa. The analysis undertaken has shown that the challenges experienced in Malawi are similar in nature to those experienced elsewhere, and the findings are in line with previous research on CB-DRR challenges in Asia (Shaw, 2006), South America (Maskrey, 2011) and Africa (van Niekerk \& Coetzee, 2012). This indicates that the development of improved CB-FRM strategies, based on a detailed understanding of local challenges, can contribute to the creation of a good practice for effective CB-DRR on a far larger, international scale. 
The study presented in this paper is a part of an on-going research project that will further look into the ways of overcoming identified challenges; more specifically by understanding the pathways for the increased role of local knowledge in CB-FRM in Malawi. 


\section{References}

Adeloye, A.J., Mwale, F.D., \& Dulanya, Z. (2015). A metric-based assessment of flood risk and vulnerability of rural communities in the Lower Shire Valley, Malawi. Proceedings of the International Association of Hydrological Sciences, 370, DOI:10.5194/piahs-370-139-2015

Ali, A., Malwanda, C., \& Suliman, Y. (1999). Official development assistance to Africa: an overview. Journal of African Economies, 8, 504-527. DOI:10.1093/jae/8.4.504

Andrews, N. (2009).Foreign aid and development in Africa: What the literature says and what the reality is. Journal of African Studies and Development, 1, 008-015. Retrieved from http://www.academicjournals.org/journal/JASD/article-abstract/9F397B48420

Atkins. (2011). Integrated Flood Risk Management Plan for the Shire Basin project Inception Report-Final. Retrieved from MASDAP:

www.masdap.mw/documents/258/download

Bazeley, P. (2013). Qualitative data analysis: practical strategies. SAGE Publications: London

Blaikie, P.M., Cannon, T., Davis, I., \& Wisner, B. (1994). At risk: natural hazards, people's vulnerability and disasters. Routlege: Oxford

Bollin, C., \& Hidajat, R. (2013). Community- based risk index: Pilot implementation in Indonesia. In J. Birkman (Ed.), Measuring Vulnerability to Natural Hazards: Towards Disaster Resilient Societies (pp. 271-290). Bonn: UNU-IEH, United Nations University Press

Brooks, N. (2003). Vulnerability, risk and adaptation: A conceptual framework. Tyndall Centre Working Paper No. 38. Tyndall Centre for Climate Change Research.

Brown, D. (2011). Making the linkages between climate change adaptation and spatial planning in Malawi. Environmental Science and Policy, 14, 940-949. DOI: http://doi.org/10.1016/j.envsci.2011.07.009

Bryman, A. (2012). Social research methods. Oxford: Oxford University Press.

Carby, B. (2015). Beyond the community: integrating local and scientific knowledge in the formal development approval process in Jamaica. Environmental Hazards, 14, 252 269. DOI: http://dx.doi.org/10.1080/17477891.2015.1058740

Chhibber, A., \& Laajaj, R. (2008). Disasters, Climate Change and Economic Development in Sub-Saharan Africa: Lessons and Direction. Journal of African Economies, 17, ii7ii49. DOI: https://doi.org/10.1093/jae/ejn020 
Chidanti-Malunga, J. (2011). Adaptive strategies to climate change in Southern Malawi.

Physics and Chemistry of the Earth, 36, 1043-1046. DOI:

http://doi.org/10.1016/j.pce.2011.08.012

Chikwawa District Council. (2014). Disaster Contingency Plan 2014-201.

Chiusiwa, J. (2015). Malawi: National progress report on the implementation of the Hyogo Framework of Action (2013-2015). Retrieved from PreventionWeb: http://www.preventionweb.net/english/hyogo/progress/reports/v.php?id=41874\&pid:2 $\underline{23}$

Dekens, J. (2007). Local knowledge for disaster preparedness: A literature review. Retrieved from PreventionWeb: http://www.preventionweb.net/files/2693_icimod8fc84ee621cad6e77e083486ba6f9cd b.pdf.

Department of Surveys. (2017). Malawi Spatial Data Platform. Retrieved January 10, 2017, from http://www.masdap.mw/

Dumaru, P. (2010). Community-based adaptation: enhancing community adaptive capacity in Druadrua Island, Fiji. Wiley Interdisciplinary Reviews: Climate Change, 1, 751-763. DOI: $10.1002 /$ wcc. 65

Gaillard, J.C., \& Mercer, J. (2013). From knowledge to action: Bridging gaps in disaster risk reduction. Progress in Human Geography, 37, 93-114. DOI: https://doi.org/10.1177/0309132512446717

Gero, A., Méheux, K., \& Dominey-Howes, D. (2011). Integrating community based disaster risk reduction and climate change adaptation: Examples from the Pacific. Natural Hazards and Earth System Science, 11, 101-113. DOI:10.5194/nhess-11-101-2011

Government of Malawi (GoM). (2006). Malawi's National Adaptation Programme of Action (NAPA). Lilongwe: Ministry of Mines, Natural Resources and Environment.

Government of Malawi (GoM). (2010). Malawi Growth and Development Strategy II 20112016. Lilongwe: Ministry of Finance and Development Planning.

Government of Malawi (GoM). (2015a). Malawi Flood Emergency Recovery ProjectEnvironmental and Social Management Framework. Lilongwe: Ministry of Finance, Economic Planning and Development. Retrieved from: https://www.finance.gov.mw/index.php/documents/doc_view/211-esmf-malawifloods-emergency-recovery-project-mferp 
Government of Malawi (GoM). (2015b). Floods Post Disaster Needs Assessment. Retrieved from Prevention Web: http://reliefweb.int/sites/reliefweb.int/files/resources/Malawi2015-Floods-Post-Disaster-Needs-Assessment-Report.pdf.

Government of Malawi (GoM). (2015c). National Disaster Risk Management Policy. Lilongwe: Department of Disaster Management Affairs.

Grady, A., Gersonius, B., and Makarigakis, A. (2016). Taking stock of decentralized disaster risk reduction in Indonesia. Natural Hazards Earth System Sciences, 16, 2145-2157. DOI:10.5194/nhess-16-2145-2016

Grindle, M.S. (2004). Good Enough Governance: Poverty Reduction and Reform in Developing Countries. Governance, 17, 525-548. DOI: 10.1111/j.09521895.2004.00256.x

Habitat III Secretariat. (2015). Habitat III Issue Papers 17- Cities and climate change and disaster risk management. New York: HIII Secretariat Retrieved from ALNAP: http://www.alnap.org/resource/20562

Heijmans, A. (2009). The social life of community-based disaster risk reduction: origin, politics and framing (Disaster Studies Working Paper 20). Retrieved from University College London: https://www.ucl.ac.uk/hazardcentre/resources/working_papers/working_papers_folder /wp20Hewitt, K. (1983). The idea of calamity in a technocratic age. In K. Hewitt (Ed.), Interpretations of calamity from the viewpoint of human ecology (pp.3-32). Allen and Urwin Inc.

Hiwasaki, L., Luna, E., Syamsidik, \& Shaw, R. (2014). Process for integrating local and indigenous knowledge with science for hydro-meteorological disaster risk reduction and climate change adaptation in coastal and small island communities. International Journal of Disaster Risk Reduction, 10, 15-27. DOI:

http://doi.org/10.1016/j.ijdrr.2014.07.007

Howlett, M. \& Cashmore, B. (2009). The Dependent Variable Problem in the Study of Policy Change: Understanding Policy Change as a Methodological Problem. Journal of Comparative Policy Analysis: Research and Practice. Vol. 11 , No. 1. DOI: $0.1080 / 13876980802648144$

Jahangiri, K., Izadkhah, Y.O., and Tabibi, S.J. (2011). A comparative study on communitybased disaster management in selected countries and designing a model for Iran. Disaster Prevention and Management, 20, 82-94.

DOI: http://dx.doi.org/10.1108/09653561111111108 
Kienberger, S. (2013). Mapping vulnerability- Integration of GIScience and participatory approaches at the local and district levels. In J. Birkmann (Ed.), Measuring Vulnerability to Natural Hazards: Towards Disaster Resilient Societies (pp. 401-422). Bonn: UNU-IEH, United Nations University Press.

Maskrey, A. (1989). Disaster Mitigation: A community based approach. London: Oxfam GB. Maskrey, A. (2011). Revisiting community-based disaster risk management. Environmental Hazards, 10, 42-52. DOI: https://doi.org/10.3763/ehaz.2011.0005

Mason, M. (2010). Sample Size and Saturation in PhD Studies Using Qualitative Interviews. Forum: Qualitative Social Research, 11, Retrieved from http://www.qualitativeresearch.net/index.php/fqs/article/view/1428/3027

Mercer, J. (2010). Disaster Risk Reduction or Climate Change Adaptation: Are we reinventing the wheel. Journal of International Development, 22, 247-264. DOI: 10.1002/jid.1677

Mercer, J., Kelman, I., \& Dekens, J. (2009). Integrating Indigenous and Scientific Knowledge for Disaster Risk Reduction. In R. Shaw, A. Sharma, \& Y. Takeuchi (Ed.), Indigenous Knowledge and Disaster Risk Reduction: From Practice to Policy (pp. 115-131). Nova Science Publishers.

Mercer, J., Kelman, I., Llyod, K., \& Suchet-Pearson, S. (2008). Reflections on use of participatory research for disaster risk reduction. Area, 40, 172-183. DOI: 10.1111/j.1475-4762.2008.00797.x

Mercer, J., Kelman, I., Taranis, L., \& Suchet-Pearson, S. (2010). Framework for integrating indigenous and scientific knowledge for disaster risk reduction. Disasters, 34, 214 239. DOI: $10.1111 / \mathrm{j} .1467-7717.2009 .01126 . x$

Mijoni, P.L., \& Izadkhah, Y.O. (2009). Management of floods in Malawi: case study of the Lower Shire River Valley. Disaster Prevention and Management, 180, 490-503. DOI: http://dx.doi.org/10.1108/09653560911003688

Mwale, F.D., Adeloye, A.J., \& Beevers, L. (2015). Quantifying vulnerability of rural communities to flooding in SSA: A contemporary disaster management perspective applied to the Lower Shire Valley, Malawi. International Journal of Disaster Risk Reduction, 12, 172-187. DOI: http://doi.org/10.1016/j.ijdrr.2015.01.003

National Statistical Office. (2008). Malawi Population and Housing Census 2008: Main report. Zomba: National Statistical Office.

National Statistical Office. (2012). Integrated Household Survey 2010-2011- Household Socio-economic characteristics report. Zomba: National Statistical Office. 
Nillson, A., Shela, O.N., \& Chavula, G. (2010). Flood risk management strategy: mitigation, preparedness, response and recovery. Lilongwe: Department of Disaster Management Affairs

Nkomwa, E.C., Kalanda Joshua, M., Ngongondo, C., Monjerezi, M., \& Chipungu, F. (2014). Assessing indigenous knowledge systems and climate change adaptation strategies in agriculture: A case study of Chagaka Village, Chikhwawa, Southern Malawi. Physics and Chemistry of the Earth, 67-69, 164-172. DOI: http://doi.org/10.1016/j.pce.2013.10.002

Nsanje District Council. (2015). Nsanje District Council Contingency Plan 2015-2016. O’Keefe, P., Westgate, K., \& Wisner, B. (1976). Taking the naturalness out of natural disasters. Nature, 260, 566-567. DOI: doi:10.1038/260566a0

Pangapanga, P.I., Jumbe, C.B., Kanyanda, S., \& Thangalimodzi, L. (2012). Unravelling strategic choices towards droughts and floods' adaptation in Southern Malawi. International Journal of Disaster Risk Reduction, 2, 57-66. DOI: http://doi.org/10.1016/j.ijdrr.2012.08.002

Pardoe, J., Kloos, J. \& Assogba, N.P. (2016). Seasonal Variability: Impacts, Adaptations and the Sustainability Challenge. In J. Yaro, \& J. Hesselberg (Ed.), Adaptation to Climate Change and Variability in Rural West Africa (pp.41-57). Cham: Springer International Publishing.

Pauw, K., Thurlow, J., Bachu, M., \& van Seventer, D.E. (2011). The economic costs of extreme weather events: a hydrometeorological CGE analysis for Malawi.

Environment and Development Economics, 16, 177-198. DOI: https://doi.org/10.1017/S1355770X10000471

Rudari, R., Beckers, J., De Angeli, S., Rossi, L. \& Trasforini, E. (2016). Impact of Modelling Scale on Probabilistic Flood Risk Assessment: The Malawi Case. E3S Web of Conferences 7, 04015. DOI: https://doi.org/10.1051/e3sconf/20160704015

Scolobig, A., Priot, T., Schoter, D., Jorin, J., \& Patt, A. (2015). Towards people-centred approaches for effective disaster risk management: Balancing rhetoric with reality. International Journal of Disaster Risk Reduction, 12, 202-212. DOI: http://doi.org/10.1016/j.ijdrr.2015.01.006

Shaw, R. (2006). Critical Issues of Community Based Flood Mitigation: Examples from Bangladesh and Vietnam. Journal of Science \& Culture, 1-2, 1-17. Retrieved from 
https://www.researchgate.net/publication/228340311_Critical_Issues_of_Community_ Based_Flood_Mitigation_Examples_From_Bangladesh_and_Vietnam

Shaw, R. (2012). Overview of Community-Based Disaster Risk Reduction. In R. Shaw (Ed.), Community-Based Disaster Risk Reduction (pp.3-17). Bingley: Emerald Insights.

Shela, O.N., Thompson, G., Jere, P., \& Annandale, G. (2008). Analysis of Lower Shire Floods: a flood risk reduction and recovery programme proposal. Lilongwe: Department of Disaster Management Affairs

Smucker, T.A., \& Wisner, B. (2008). Changing household responses to drought in Tharaka, Kenya: vulnerability, persistence and challenge. Disasters, 32, 190-215. DOI: $10.1111 / \mathrm{j} .1467-7717.2007 .01035 . \mathrm{x}$

Stephenson, M.H., \& Penn, I.E. (2005). Capacity building of developing country public sector institutions in the natural resource sector. Geological Society, London, Special Publications, 250, 185-194. DOI: 10.1144/GSL.SP.2005.250.01.17

The World Bank. (2010). Disaster Risk Management in Malawi- Country Note. Retrieved from GFDRR:

https://www.gfdrr.org/sites/gfdrr.org/files/documents/Malawi_DRM_Program_July2010.pdf

Twigg, J. (2009).Characteristics of a disaster-resilient community: a guidance note.

Teddington: DFID Disaster Risk Reduction NGO Interagency Group.

UNESCAP. (2009). What is good governance?. Retrieved from UNESCAP: http://www.unescap.org/resources/what-good-governance.

UNISDR. (2009). 2009 UNISDR Terminology on Disaster Risk Reduction. Geneva: UNISDR.

UNISDR. (2015). Sendai Framework for Disaster Risk Reduction 2015-2030. Geneva: UNISDR.

USGS. (2017). Earth Explorer. Retrieved January 7, 2017, from https://earthexplorer.usgs.gov/

van Niekerk, D., \& Coetzee, C. (2012). African Experiences in Community-Based Disaster Risk Reduction. In R. Shaw (Ed.), Community-Based Disaster Risk Reduction (pp. 333-349). Bingley: Emerald Insights.

Waylen, K., \& Martin-Ortega, J. (2013). Report on knowledge exchange workshops on an ecosystem services approach. United Kingdom: The James Hutton Institute.

Wisner, B., Blaikie, P., Cannon. T \& Davis, I. (2004). At Risk: natural hazards, people's vulnerability, and disasters. Second Edition. Oxford: Routledge 


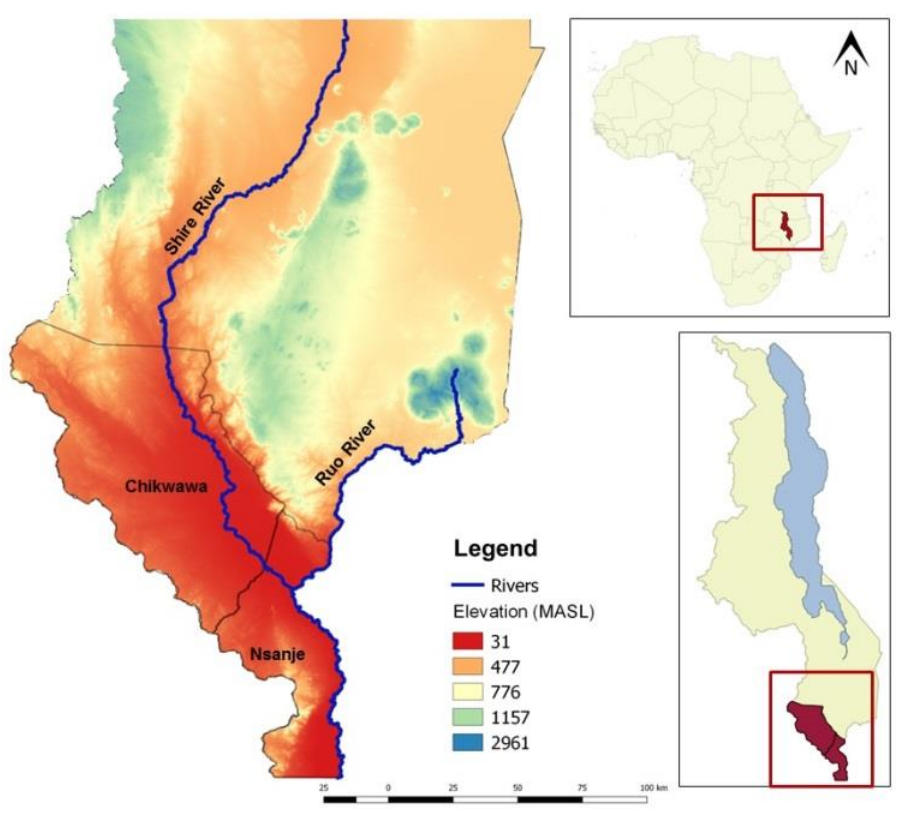

Figure 1: Location of the case study area

Table 1: Focus group discussions overview

\begin{tabular}{|c|c|c|c|c|c|}
\hline $\begin{array}{l}\text { Stakeholder } \\
\text { group }\end{array}$ & District & $\begin{array}{l}\text { Group } \\
\text { Village } \\
\text { Head } \\
\text { (GVH) }\end{array}$ & $\begin{array}{l}\text { Traditional } \\
\text { Authority } \\
\text { (TA) }\end{array}$ & $\begin{array}{l}\text { Number of } \\
\text { participants }\end{array}$ & Male* Female $^{* *}$ \\
\hline
\end{tabular}

\begin{tabular}{lllllll}
\hline $\begin{array}{l}\text { Communities } \\
\text { (VCPC) }\end{array}$ & Nsanje & Bitrinyu & Ndamera & 10 & 7 & 3 \\
$\begin{array}{l}\text { Communities } \\
\text { (VCPC) }\end{array}$ & Nsanje & Nyathando & Ndamera & 11 & 8 & 3 \\
$\begin{array}{l}\text { Communities } \\
(\text { VCPC) }\end{array}$ & Nsanje & Mbenje & Mbenje & 7 & 5 & 2 \\
$\begin{array}{l}\text { Communities } \\
\text { (VCPC) }\end{array}$ & Nsanje & Nyan'ga & Mbenje & 10 & 6 & 4 \\
$\begin{array}{l}\text { Communities } \\
\text { (VCPC) }\end{array}$ & Chikwawa & Chikhamwi & Kasisi & 16 & 12 & 5 \\
$\begin{array}{l}\text { Communities } \\
\text { (VCPC) }\end{array}$ & Chikwawa & Medram & Milima & 7 & 3 & 4 \\
$\begin{array}{l}\text { Communities } \\
(\text { VCPC) }\end{array}$ & Chikwawa & Khunghbwe & Ngowe & 9 & 5 & 4 \\
NGOs & Nsanje & - & - & 3 & 3 & 0 \\
NGOs & Nsanje & - & - & 8 & 7 & 1 \\
DCPC & Nsanje & - & - & 9 & 8 & 1 \\
DCPC & Chikwawa & - & - & 17 & 5 \\
\hline
\end{tabular}


$*^{* * *}:$ In all but one of the FGDs, there was a representation of both female and male participants. A higher proportion of women was represented in FGDs with communities compared to NGOs and DCPCs.
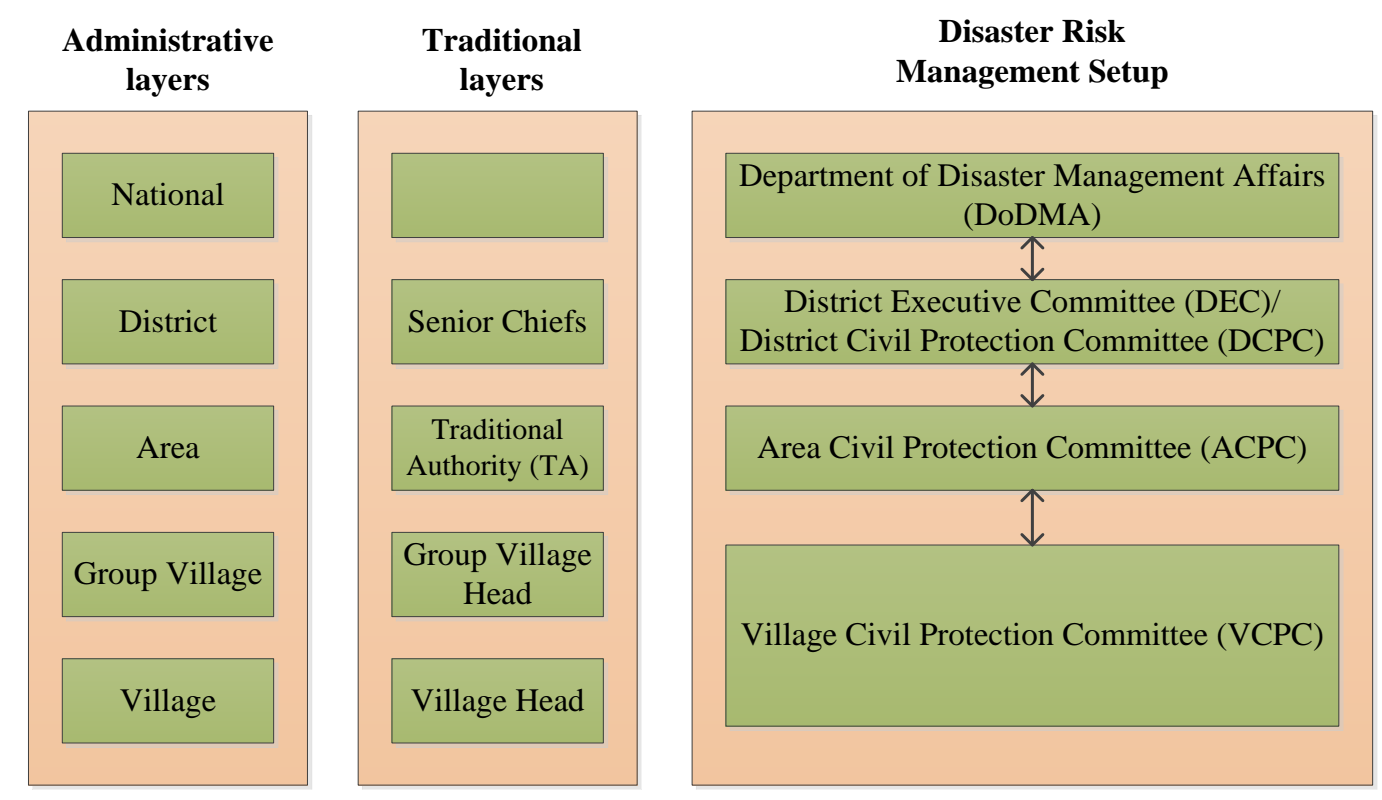

Figure 2: Administrative and traditional layers in Malawi, and disaster risk management institutional setup in Malawi

Table 2 Overview of the main research results and findings

Table 2a Roles and challenges of different stakeholder groups in CB-FRM in Malawi

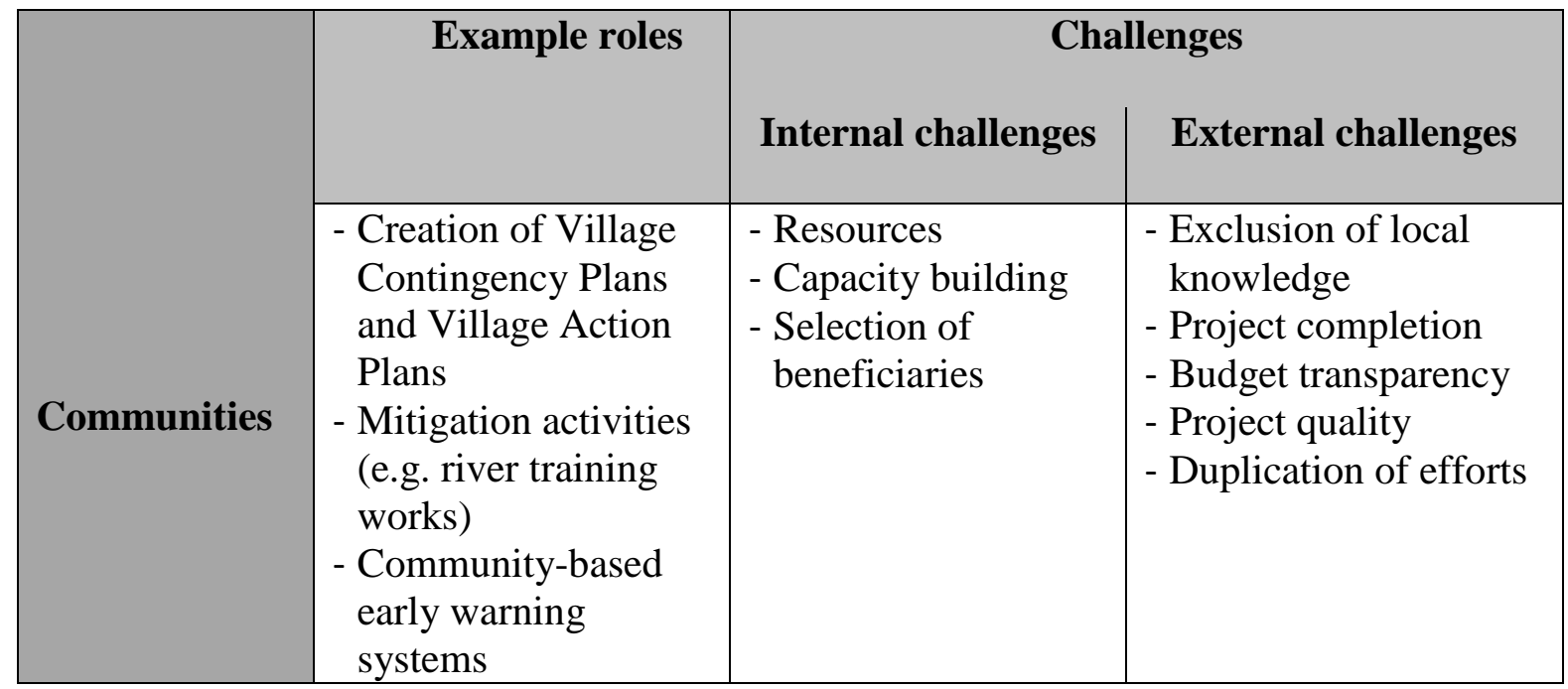




\begin{tabular}{|c|c|c|c|}
\hline NGOs & $\begin{array}{l}\text { - Capacity building } \\
\text { activities } \\
\text { - Community-based } \\
\text { early warning } \\
\text { systems } \\
\text { - Relief iteams } \\
\text { distribution }\end{array}$ & $\begin{array}{l}\text { - Relationship with } \\
\text { donors } \\
\text { - Coordination with } \\
\text { different NGOs } \\
\text { - Data and } \\
\text { information sharing } \\
\text { - Project } \\
\text { sustainability } \\
\text { - Community } \\
\text { ownership }\end{array}$ & $\begin{array}{l}\text { - Aid-dependency } \\
\text { syndrome } \\
\text { - Communal activities } \\
\text { fail } \\
\text { - Power relations } \\
\text { within communities } \\
\text { - Unequal spatial } \\
\text { coverage of projects } \\
\text { withing districts } \\
\text { - Project sustainability } \\
\text { - Community } \\
\text { ownership }\end{array}$ \\
\hline $\begin{array}{l}\text { Local } \\
\text { government }\end{array}$ & $\begin{array}{l}\text { - Coordination of all } \\
\text { DRR activities at the } \\
\text { district level through } \\
\text { District Civil } \\
\text { Protection } \\
\text { Committee }\end{array}$ & $\begin{array}{l}\text { - Resources } \\
\text { - Some sectors left } \\
\text { out in the planning } \\
\text { phase }\end{array}$ & $\begin{array}{l}\text { - Monitoring } \\
\text { - Lack of community } \\
\text { participation } \\
\text { - Aid- dependecy } \\
\text { - Power relations } \\
\text { within community } \\
\text { - Duplication of efforts } \\
\text { - Transparency and } \\
\text { accountability by } \\
\text { NGOs }\end{array}$ \\
\hline
\end{tabular}

Table 2b Legal and policy context for DRR in Malawi

\begin{tabular}{|c|c|c|}
\hline & National level & $\begin{array}{c}\text { Local levels (District, } \\
\text { Traditional Authority, Group } \\
\text { Village Headman) }\end{array}$ \\
\hline $\begin{array}{l}\text { Administrative } \\
\text { level }\end{array}$ & $\begin{array}{l}\text { - Disaster Preparedness and Relief } \\
\text { Act (1991) } \\
\text { - National Disaster Risk } \\
\text { Management Policy (2015) } \\
\text { - Malawi Growth and } \\
\text { Development Strategy II (2011- } \\
\text { 2016) } \\
\text { - National Adaptation Programmes } \\
\text { of Action (2006) }\end{array}$ & $\begin{array}{l}\text { - Contingency Plans } \\
\text { - Disaster Management Plant (not } \\
\text { available at the time of data } \\
\text { collection) }\end{array}$ \\
\hline
\end{tabular}

